\title{
Review of electrostatic system parameters, charged droplets characteristics and substrate impact behavior from pesticides spraying
}

\author{
Samuel Appah ${ }^{1}$, Pei Wang ${ }^{2 *}$, Mingxiong Ou ${ }^{1}$, Chen Gong ${ }^{2}$, Weidong Jia ${ }^{1 *}$ \\ (1. Key Laboratory of Modern Agricultural Equipment and Technology, Ministry of Education, Jiangsu University, Zhenjiang 212013, \\ Jiangsu, China; 2. Key Laboratory of Plant Protection Engineering, Ministry of Agriculture and Rural Affairs, Jiangsu University, \\ Zhenjiang 212013, Jiangsu, China)
}

\begin{abstract}
Electrostatic spraying application is adopted in crop protection to prevent pest infestation, to improve product quality and to maximize yield. It involves a superposition of charges to pesticide spray droplets to attract substrate ions at obscured surfaces. The droplets wraparound effect reduces off-target deposition, enhances on-target spray and invariably improves spray efficiency. Electrostatic spraying system works effectively at optimum parameters in combination with charging voltages, application pressures, spraying height regimes, flow rate, travel speed, electrode material, and nozzle orientation. Many combinations of the system parameter settings have been systematically used by researchers for the electrostatic application, but there are unknown specific optimum parameters combinations for pesticide spraying. Since droplets chargeability influences the effectiveness of electrostatic spraying system, the parameters that produce ideal charge to mass ratio determine the functionality of the spraying deposition, retention and surface coverage. This article, therefore, analyses electrostatic system parameters that produce suitably charged droplets characteristics for effective impacting behavior of pesticides on substrates. Increasing applied voltages consequently maximizes charge-mass ratio to optimum and starts declining upon further increase in voltages beyond a critical point. This review further proposes the selection of an optimum electrostatic parameters combination that yields optimum droplets chargeability in pesticide application. Also, it is necessary to investigate the charge property of substrates prior to pesticide application in order to superpose the right opposite charge on spray droplets at rupture time during electrostatic spraying system.
\end{abstract}

Keywords: electrostatic spraying, charged droplets, substrates, deposition, wraparound, charge-mass ratio DOI: $10.25165 /$ j.ijabe.20191202.4673

Citation: Appah S, Wang P, Ou M X, Gong C, Jia W D. Review of electrostatic system parameters, charged droplets characteristics and substrate impact behavior from pesticides spraying. Int J Agric \& Biol Eng, 2019; 12(2): 1-9.

\section{Introduction}

Integrated pest management has gone through several technical evolutions to create good conditions for plant growth and development ${ }^{[1,2]}$. There are different strategies in pest management for various degrees of the control efficiency including cultivating, biological, mechanical and chemical methods. Among these strategies, the chemical application has gained usefulness over decades and it is considered as the quickest and effective approach in plant protection ${ }^{[3,4]}$. The chemical active ingredients are often used to control pest infestation and to maximize yield ${ }^{[5]}$. The pesticides active ingredients either from natural or synthetic sources have different levels of toxicity and rheological properties. Hence, when selecting and applying any pesticide, overcoming excessive spray wastage from undue drifting onto non-targets should be considered ${ }^{[6,7]}$. As a result, ecological

\section{Received date: $2018-09-25$ Accepted date: 2019-03-13}

Biographies: Samuel Appah, MSc, research interests: plant protection engineering, Email: askappah@yahoo.com; Mingxiong Ou, PhD, Associate Professor, research interests: plant protection engineering, Email: myomx@ujs.edu.cn; Chen Gong, PhD, research interests: spraying technology, Email: chengong@ujs.edu.cn.

*Corresponding author: Pei Wang, PhD, Associate Professor, research interests: integrated pest management and precision agriculture. Key Laboratory of Plant Protection Engineering, Ministry of Agriculture and Rural Affairs, Jiangsu University, Zhenjiang 212013, Jiangsu, China. Email: wangpei@live.cn; Weidong Jia, PhD, Professor, research interests: plant protection engineering. Xuefu Road 301, Jingkou District, Zhenjiang 212013, China. Tel: +86-511-88780356, Email: jiaweidong@ujs.edu.cn. imbalance and groundwater pollution will be avoided ${ }^{[8]}$. Although the potency of pesticides active ingredients is determined mostly by the product's mode of action, application mechanism can also aid the functionality of the chemicals. Therefore, improving the efficiency of spray necessitates the need to include the surface-active agents, which is also known as the adjuvants, in pesticide formulation. The adjuvants serve the purpose of lowering the surface tension of the solution to improve the droplets' spreading and impinging behavior on substrates ${ }^{[9,10]}$, while application systems significantly influence spray droplet characteristics, deposition and retention.

Conventionally, to enhance application effect, different spraying systems and nozzle configurations are selected by adjusting system parameters. The nozzle type, position, angle, as well as system parameters including flow rate and application pressure, invariably affect spray characteristics such as the droplet sizes, velocity and spray swath ${ }^{[11-13]}$. Though the application system improves on static properties of spray on adaxial surfaces, approaches that furtherly enhance dynamic behavior of droplets on both abaxial and adaxial surfaces can bridge most spraying inefficiency. Such an innovative approach should concentrate more droplets on substrates to prevent drift and rebound by superposition of charges to spray droplets ${ }^{[8,14,15]}$. For an efficient application, pesticides must reach target substrates for interactive effect so that the product ingredient can impact positively with reduced drift. This requires combining electrostatic charges and surfactant ions in the spray to ensure wraparound deposition effect on substrates architecture. 
Recently electrostatic spraying system is an innovative plant protection strategy yearning to overcome the shortfalls in pesticide wastage, groundwater pollution and environmental contamination $^{[16,17]}$. It is a system in which an electrical charge is superposed on droplets to impact on substrates for deposition, attraction, and retention. The charge injection to droplets greatly enhances abaxial and adaxial spray deposition and retention ${ }^{[18]}$, improves canopy penetration at reduced application rate. Works on both abaxial and adaxial substrates deposition from electrostatic spraying are ongoing ${ }^{[19]}$. This paper reviews the parameters of the system, charged droplet characteristics and impact behavior on substrates. Mainly the substrates to deposit charged spray droplets must be able to absorb the ingredients. Some plants and insect pests largely possessions in architecture to attract electrostatic charges injected to spray droplets for substrate adsorption. Such substrate charges must be taken into consideration in electrostatic pesticide spraying so that the required charge can be produced by the electrode for effective application. A high voltage charge is often pinned to spray droplets from electrode attachment to nozzles. The technology enhances agrochemical spraying by improving spray droplet characteristics, droplet deposition, and wraparound effect. The characteristic feature of the charged droplets and their impact behavior on substrates are attributable functions of electrostatic system parameters.

In pesticide spraying system, variable parameters have been adopted for the application. Extensive studies on droplets characteristics at different spraying parameters in the conventional system have been reviewed ${ }^{[20-22]}$, while that of the electrostatic system is currently gaining momentum and needs to be analyzed ${ }^{[23]}$. The system properties include nozzle type, angle, electrodeposition and size, apply voltage, pressure, flow rate, nozzle spacing and spraying height or distance. Thanks to the electrostatic spraying, the environmental pollution caused by pesticides spraying on non-target sites have been reduced ${ }^{[16,24]}$. Since electrostatic spraying was applied in pesticide spraying, several parameters have been tested to achieve suitable parameter combinations for efficient application $^{[25]}$, but without optimization selection. While some researchers sprayed at reduced applied voltages, low spraying height regimes, minimum electrode distance, and air-assisted induction nozzles, others, on the other hand, applied different parameter combinations to achieve different charged droplets targets. Meanwhile, electrostatic spraying aims at obtaining maximum chargeability for both adaxial and abaxial deposition. The best parameter combinations to ensure the effective deposition of active ingredients on the substrates deserves in-depth investigation. This article therefore analyses the droplets' characteristics and their impact behavior on substrates at different application parameters in the electrostatic spraying of pesticides.

\section{Electrostatic spraying application of pesticides}

Electrostatics is an entrained electric charge that a body possesses at the stationary state. The static electric charge accumulates on the surface of substrates upon contact with other surfaces. The substrate is grounded neutral to attract generated electrical charge for an interactive effect. Predominantly, the system has been applied in many fields such as electrostatic coating, precipitation, AC impedance, and electrostatic spraying. In coatings, the principle is used to apply electrical charges to either powdered particles or atomized liquid for painting a conductive workpiece $^{[26]}$. Conduction, induction, corona or triboelectrification methods are used to charge spray droplets electrostatically. But induction charging has been considered as one of the most reliable methods in pesticide application, because it prevents direct injection of high voltage to spray liquid, and utilizes small current capacity with low electric field strength than air breakdown strength $^{[27]}$. Charging by induction increases droplets chargeability by placing electrodes slightly in front of droplets rupture point to prevent electrode wetting by dispersed spray droplets $^{[28,29]}$. Electrostatic spraying adopts the Coulombic forces $\left(F_{1}=q \cdot E\right)$ in operation where droplets emitting from nozzle aperture is raised to a high potential to overcome gravitational force $\left(F_{2}=\right.$ $m \cdot g$ ). The entrained electrical charge depends greatly on the capacity of an embedded electrode in the nozzle cap. Amalgamation of inertial, gravitational and electrostatic forces contribute to spray chargeability in electrostatic spraying system ${ }^{[30]}$. Electrostatic principle helps to improve wraparound deposition of droplets on substrates at reduced spray drifts and chemical wastage.

The principle of electrostatic spraying was introduced into agricultural plant protection in the late 20th century. In the early 1930s, the application of electrostatic spraying technology for droplets deposition began, and it was 1980's that the principle was transferred into agrochemical application ${ }^{[31]}$. In the 21 st century, this technology is expected to be applied more widely by increasing charged droplets deposition on difficult-to-reach substrates ${ }^{[32]}$. The technology has radically changed the face of pesticide application where pests residing at both abaxial and adaxial leaf surfaces are completely exterminated, as well as enhancing efficiency and bio-efficacy of spraying on target substrates ${ }^{[15,33]}$. Electrostatic application principles for pesticides spraying are classified into three interlinked phases of electrodynamics consisting of electrode selection, configuration and superposition of electrode charge to spray droplets; hydrodynamics - liquid flow and atomization in the nozzle; and aerodynamics - final phase where break-up charged droplets are directed to target substrates to cause-effect (Figure 1) ) $^{[34,35]}$.

In crop protection, electrostatic spraying is widely used for the application of plant protection products. Ever since, many types of equipment ranging from manual or motorized backpack sprayers, tractor mounted sprayers, man-aerial sprayers, to the unmanned aerial vehicle (UAV) has been designed and tested for electrostatic spraying of pesticides ${ }^{[36-41]}$. However, to overcome the human risk factor during pesticide spraying, an electrostatic spraying technology could be incorporated into the robotic pesticide spraying system in plant protection. The development and commercialization of electrostatic spraying systems initially were not economical in usage by local farmers, because it was motorized and operated by heavy equipment. Therefore, the invention of hand pressure electrostatic knapsack sprayer following the introduction of the air-assisted electrostatic nozzle was put forward to enhance the efficiency of pesticide application ${ }^{[42]}$. The coupling effect is applied in electrostatic spraying of agrochemicals in plant protection due to the powdery and fluidized properties of plant protection products. In agriculture, electrostatics spraying improves plant canopy penetration at both topside and underside substrates which invariably reduces the rate of application. It is considered as one of the suitable techniques to overcome problems associated with agrochemical spraying in the conventional system such as volatility and drift of spray droplets from temperature and wind effects. The application of electrostatic force in agrochemical spraying enhances the droplets deposition and bio-efficacy ${ }^{[18,43,44]}$. To efficiently protect agricultural products 
from pest and disease infestation with agrochemicals, spraying should be done electrostatically ${ }^{[45]}$. An aerial electrostatic application of pesticides was investigated by Kirk et al. ${ }^{[36]}$ with maximum droplets deposition on surfaces than that of the conventional system. The experiment was conducted by injecting charges to a prototype nozzle in aerial electrostatic spraying and compared the spraying performance with conventional spraying. Electrostatics application in crop protection has witnessed many developments in optimizing the system parameters worthy of recommendation ${ }^{[46,47]}$.

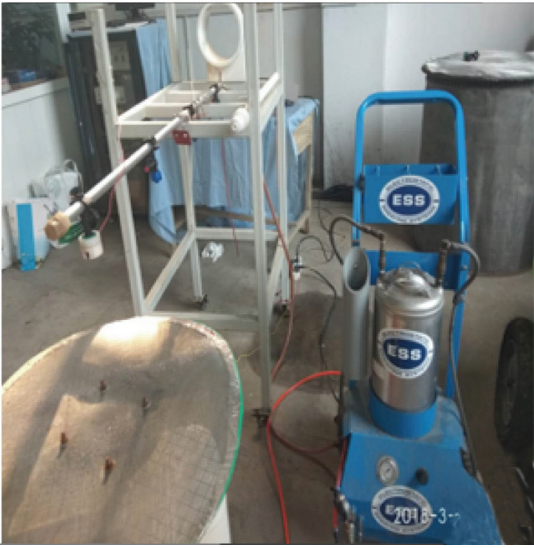

a. An electrostatic system from the company ESS

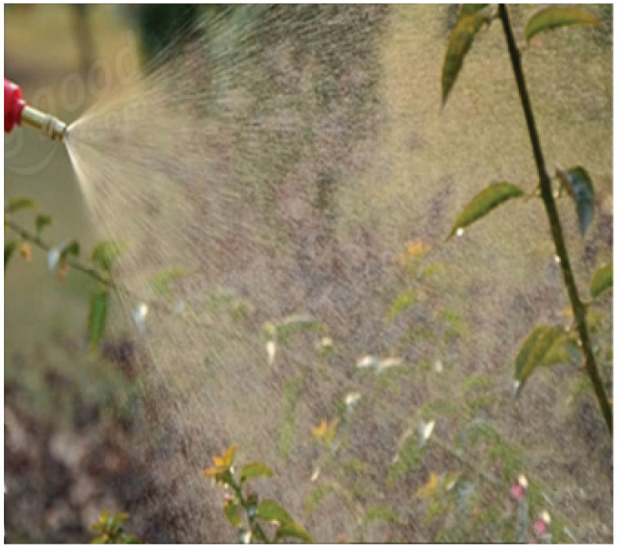

b. Charged droplets deposition on abaxial and adaxial surfaces

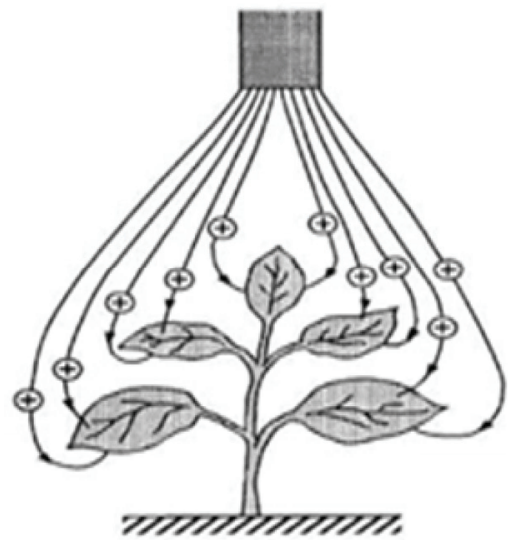

c. Adsorption trajectory of charged droplets onto leaf substrate architecture

Figure 1 Electrostatic Spraying

\section{Electrostatic system properties}

Spraying parameters for electrostatic system embody all mechanisms and procedures combined to pressurize formulation onto respective substrates. They influence droplets characteristics and effectiveness of droplets deposition when proper combinations of system parameters are followed. Different electrostatic system parameters have been adopted by researchers for pesticide application, but with little proposition towards specific optimum parameter combination for optimum spraying.

\subsection{Nozzle type and electrode material}

The basic aperture which is responsible for dispensing pesticides spray onto droplets under the influence of flow pressure is the nozzle. In the electrostatic system, nozzles' capability to produce desirable charged droplet sizes and coverage at minimal spray drift determines application efficiency. A capacitive nozzle type with ring electrode embodiment has been used to provide high electrical charge outside droplets breakup point, which resulted in maximum spray deposition on targeted substrates ${ }^{[48]}$. In earlier studies, air-assisted twine-type, flat fan, and spinning disc nozzles were commonly mounted for an electrostatic pesticide spraying ${ }^{[49]}$. Zhang et al. ${ }^{[6]}$ also experimented conical electrostatic nozzle to assess droplets drift reduction in pesticides spraying and recorded smaller droplet sizes and higher drift potential. Also, the rotary atomizer nozzle was used for electrostatic spraying of pesticides on cotton to enhance droplet deposition on both upside and underside leaves ${ }^{[50]}$. An air-assisted induction charging nozzle at $45^{\circ}$ spray angle was utilized in electrostatic application to measure abaxial and adaxial droplets deposition on leaves ${ }^{[19]}$. Though the nozzle worked to the required demand, increasing the tip angle to maximize surface coverage could reduce operation time and chemical dosage. This is because the charged droplets have the capability to attract the substrate ions irrespective of droplet direction. Laryea and $\mathrm{No}^{[29]}$ invented a pressure-swirl nozzle for electrostatic spraying, which has the capacity to spray pesticides at low application rate, maximum deposition with minimum droplets drift to non-target substrates. Air-Assisted nozzles or pressure swirl nozzles were also utilized to apply about $90 \%$ of liquid pesticide spray ${ }^{[51]}$. Since nozzle type affects droplets charging property, understanding charging mechanisms are important to enhance the charged droplets trajectories and deposition. The need for a specialized sprayer for pesticide application led to the introduction of an air-assisted electrostatic nozzle working under the combined principle of induction charging and air-assisted nozzle in India ${ }^{[24]}$. All nozzles meant for electrostatic spraying of pesticides should be able to increase ground spray coverage to enhance the efficiency of spraying at minimum wear rate.

In the nozzle, electrode materials with different voltage capacitive properties are used to charge droplets electrostatically for spraying of pesticides. An embodiment of the electrode material in a nozzle should be in such a way, that the electronic circuitry is detached from the body for droplet charging electrostatically. The electrode material plays a major role in finely break-up particulate droplets chargeability with different material characteristics performing uniquely in charging spray droplets. Stainless Steel, Copper and Brass are considered the most common electrode materials embedded in nozzles aperture to charge droplets ${ }^{[52]}$. However, nickel oxide and carbon are also available $^{[53]}$. At constant voltage application to variable electrode materials produces different droplets chargeability, hence choosing suitable electrode material is necessary for efficient application in electrostatic spraying system ${ }^{[54,55]}$. The electrode geometrical specification, shape and constituent material directly affect droplets chargeability and overall charge-mass ratio. The electrode metals are used due to their high conduction and resistance capacities to an applied voltage. Currently, the trend in electrostatic pesticide spraying is geared towards efficient current superposition to droplets. Hence, electrodes that can maximize chargeability at minimum load intake could serve the purpose of enhancing droplets chargeability.

In developing nozzle for electrostatic charging of agrochemical droplets during spraying, Laryea and $\mathrm{No}^{[29]}$ specified the recommended dimension and shape for electrode material and put forward the need to extensively work on a procedure for selecting suitable electrode materials. A brass electrode of $12 \mathrm{~mm}$ diameter was used to charge droplets in that experiment to obtain higher charge to mass ratio and 1.3 to 2.3 folds increase in deposition at a decreasing spray drift. Meanwhile, in a comparative study, Patel 
et al. ${ }^{[56]}$ investigated the effect of stainless steel, copper, nickel, aluminum and brass electrode materials on droplets chargeability. In the study, ring electrode configuration with a peripheral diameter of $22 \mathrm{~mm}$ and the interior diameter of $15 \mathrm{~mm}$ was placed $4 \mathrm{~mm}$ from nozzle-tip of all the materials to inject charges to droplets at 0 $3.0 \mathrm{kV}$ applied voltage, $24.6 \mathrm{~L} / \mathrm{min}$ air flowing rate and a liquid flow rate of $90.0 \mathrm{~mL} / \mathrm{min}$. A $15 \mathrm{~mm}$ charging electrode distance from the nozzle tip has been found to produce high charging quantity than $10 \mathrm{~mm}^{[23]}$. Electroplating copper with nickel material in an electrode design for electrostatic spraying was found to be suitable to enhance the effectiveness of spray when optimally positioned at a distance between 2.0-3.0 $\mathrm{mm}$ from the nozzle aperture $^{[47]}$. A $1.6 \mathrm{~mm}$ electrode distance resulted in a reduction of charge-mass ratio up to $13 \%-18 \%{ }^{[37,38]}$. Due to an interactive effect of Coulombic forces on charged liquid droplets, an electrodeposition in the nozzle aperture should be relatively close to the ruptured liquid film to enhance droplets charging effectivity ${ }^{[24,57]}$. Besides the electrode material, the relative positions of the electrode connote in-depth research into optimization selection for pesticide spraying. Electrode gap that considerably increases droplets chargeability will be a welcome innovative strategy to enhance pesticide spray deposition. The overall effect indicates that the closer the gap, the better the chargeability of droplets, however, to prevent the destruction of electrode material and charged droplets atomization, it is essential to seize electrode charging wettability ${ }^{[24]}$.

\subsection{Applied voltage, pressure and flow rate}

Application of voltages to electrode material in nozzle aperture categorically increases spray droplets chargeability to a limit but further increase in applied voltage stabilizes or decreases spray droplets chargeability ${ }^{[47]}$. High voltage supply to the electrode above threshold capacity has no significant effect on maximizing droplets charge, hence the need to inject current within the recommended level. The parameters that influenced the droplets chargeability were applied voltage $(0-2 \mathrm{kV})$, flow rate $(150 \mathrm{~mL} / \mathrm{min})$, air pressure (3 bar), ring electrode geometry, mechanical and electrical properties of the solution. The decrease in chargeability emanated from a partial discharge as positive current interfered with conducting charging being caused by induction charging mechanism. Atmospheric charge interaction could also account for the dropdown charge. In an electrostatic spraying system, sprayed droplets superposed with less than $2.5 \mathrm{kV}$ charging voltage from $75 \mathrm{~mW}$ electric power produced a charge-mass ratio of over $10 \mathrm{mC} / \mathrm{kg}$ at $150 \mathrm{~mL} / \mathrm{min}$ liquid flow rate. Such a high ratio was meant to overcome the interaction between environmental ions and spray droplet charges at high spraying distance or height regime. On testing conical electrostatic nozzle in a tunnel, droplets drift was observed to be affected by wind interference but not an applied voltage. By increasing applied voltage to droplets in wind speed above $3 \mathrm{~m} / \mathrm{s}$ resulted in an increased spray drift, however, when wind speed was maintained at $0 \mathrm{~m} / \mathrm{s}$ under high voltage application of $12 \mathrm{kV}$, then resulted in a reduction of spray drift $^{[6]}$. This suggests that electrostatic spraying is much effective on the field when wind speed is minimal or cut off no matter the voltage supply.

For insect management studies in cotton farms, the pesticide application rate of $9.4 \mathrm{~L} / \mathrm{hm}^{2}$ in electrostatic system performed a similar pest mortality rate as using $46.8 \mathrm{~L} / \mathrm{hm}^{2}$ in conventional spraying system ${ }^{[35]}$. The higher performance from the lower application rate in electrostatic spraying system was probably based on charge superposition on the spray droplets. A variable liquid flow pressure between 1.8-2.5 $\mathrm{MPa}$ was subjected to applied voltages from $1.0-5.0 \mathrm{kV}$ at $60 \mathrm{~cm}$ and $90 \mathrm{~cm}$ spraying distances to measure spray chargeability. A applied voltage of $4 \mathrm{kV}$ and 2.0 MPa pressure were chosen as optimum parameter combinations to produce a charge-mass ratio of $0.27 \mathrm{mC} / \mathrm{kg}^{[29]}$. Maski ${ }^{[58]}$ operated between $0-4.0 \mathrm{kV}$ applied voltages to produce droplets charge-mass ratio from $0-5.5 \mathrm{mC} / \mathrm{kg}$. These variable parameters make it difficult for farmers to select an optimum combination for effective application hence the need for optimization selection.

In evaluating chargeability of ultrasonic nozzle, four levels of applied voltages between $1.5 \mathrm{kV}$ and $7.0 \mathrm{kV}$ supplied charges to $5 \mathrm{~mL} / \mathrm{min}, 12 \mathrm{~mL} / \mathrm{min}$ and $25 \mathrm{~mL} / \mathrm{min}$ liquid flow rates at air flow rates between $14-23 \mathrm{~m} / \mathrm{s}^{[23]}$, The optimum parameters combination that produced ideal charge-mass ratio of $1.032 \mu \mathrm{C} / \mathrm{g}$ was obtained at a maximum of $7 \mathrm{kV}$ applied voltage, lower liquid flow rate of $5 \mathrm{mlmin}^{-1}$ and higher airspeed of $23 \mathrm{~m} / \mathrm{s}$. Increasing applied voltage eventually maximized droplets chargeability, but at lower air flow speed and higher applied voltage, charging quantity declined due to corona generation between the nozzle body and induction interface ${ }^{[59]}$. Yamane and Miyazaki ${ }^{[37]}$ indicated that raising applied voltage to $4 \mathrm{kV}$ increased charge-mass ratio of spray droplets in electrostatic spraying to $0.45 \mathrm{mC} / \mathrm{kg}$ at $2.6 \mathrm{~L} / \mathrm{min}$ flow rate, without electrode-charge leakage but a further appreciation of the voltage from $6.0-8.5 \mathrm{kV}$ rather decreased droplet chargeability. By applying 2.0-4.0 bar spraying pressures at a flow rate of $150 \mathrm{~mL} / \mathrm{min}$, droplet charges increased with an increasing applied voltage, reached maximum, stabilized and began to decrease upon increasing applied voltages ${ }^{[24]}$. The increasing pressure reduced droplet sizes with an entrained higher charge than lower pressures that produced larger droplet sizes with lower chargeability. Though spraying height was not considered as a factor for the decline of chargeability in the experiment, it could account for such a phenomenon together with the parameters indicated. As pressure increased with increasing height, there is space charge interaction. A $3.25 \mathrm{kV}$ was applied to droplets at 30 psi pressure to produce $0.419 \mathrm{mC} / \mathrm{kg}$ charge-mass ratio from electrostatically induced knapsack sprayer ${ }^{[18]}$. Since deposition was not a dependent variable, judging the efficiency of the sprayer requires a further experiment to evaluate its performance. This can be achieved by measuring in-situ droplets deposition on substrates. At applied electrode voltages of $1.3 \mathrm{kV}, 2.6 \mathrm{kV}$, $4.0 \mathrm{kV}$ and $7.5 \mathrm{kV}$ levels, lower liquid flow rates of $30 \mathrm{~mL} / \mathrm{min}$, $45 \mathrm{~mL} / \mathrm{min}, 60 \mathrm{~mL} / \mathrm{min}$ and higher liquid flow rates of $250 \mathrm{~mL} / \mathrm{min}$ $450 \mathrm{~mL} / \mathrm{min}$ and $600 \mathrm{~mL} / \mathrm{min}$, the lower flow rate parameter of $30 \mathrm{~mL} / \mathrm{min}$ produced greater charge-mass ratio at $4 \mathrm{kV}$ applied voltage. Patel et al. ${ }^{[52]}$ also adopted electrostatic system parameters of less than $5.0 \mathrm{kV}$ applied voltages, $18.5 \mathrm{~L} / \mathrm{min}$ air flow rate and $93.5 \mathrm{~mL} / \mathrm{min}$ liquid flow rate to evaluate the capacitive performance of different electrode materials. Investigating the effects of charged glyphosate droplets on ryegrass in electrostatic spraying system, Martin and Lathee $\mathrm{f}^{[50]}$ subjected a formulation to applied voltages from $1-10 \mathrm{kV}$. There was an observable marginal increase in chargeability with respect to an increase in applied voltage until the highest charge-to-mass ratio of $1.686 \mathrm{mC} / \mathrm{kg}$ was obtained at the maximum $10 \mathrm{kV}$ applied voltage. $\mathrm{Yu}$ et al. ${ }^{[39]}$ also applied $10 \mathrm{kV}$ to a formulation to achieve smaller droplet sizes and spray distribution uniformity at an entrained charge of $2.65 \mathrm{mC} / \mathrm{kg}$. It is therefore not clear about the maximum CMR for $10 \mathrm{kV}$ applied voltage in the electrostatic spraying system, hence the need to investigate for the optimum level for pesticide application. From the studies, pressure and 
flow rate were the facilitating parameters for regulating droplets charges from applied voltages. Hence there is the need to investigate pressure, voltage and flow rate levels suitable to achieve maximum chargeability in pesticide spraying.

\subsection{Spraying height regimes}

In pesticide spraying, it is found that boom height has no effect on chemical efficacy but largely influences spray swath and drift. Generally, with reference to target substrates, $50 \mathrm{~cm}$ boom height is recommended for an application and increasing the height to $70 \mathrm{~cm}$ and further to $100 \mathrm{~cm}$ ensues drift potential by four and ten folds respectively in conventional spraying system. Huang et al. ${ }^{[60]}$ also flew the airplane at spraying heights of $3.7 \mathrm{~m}, 4.9 \mathrm{~m}$, and $6.1 \mathrm{~m}$ to measure crop injury from off-target droplets deposition of glyphosate. In addition, decreasing nozzle height from $50 \mathrm{~cm}$ to $30 \mathrm{~cm}$ above target reduces spray swath ${ }^{[61]}$. However, with the introduction of electrostatic principle, droplets attraction to the substrate is enormous at higher heights. Spraying height of $50 \mathrm{~cm}$ above crops canopy was adopted in electrostatic spraying using UAV and obtained an improvement in droplets deposition density $^{[40]}$. Electrostatic evaluation of an induction charging nozzle output as affected by space charge revealed that increasing spraying height regime from the target substrates decreased space charge cloud current ${ }^{[62]}$. The interaction between the spray cloud and surrounding air decreases the entrained space current of droplets upon reaching the substrates when the distance is large ${ }^{[32]}$. As charges are imposed on the droplets, Patel et al. ${ }^{[24]}$ observed that decreasing spraying vertical height from $50 \mathrm{~cm}$ to $4 \mathrm{~cm}$ rather produced higher chargeability of $8.7 \mathrm{mC} / \mathrm{kg}$. While $50 \mathrm{~cm}$ height regime produced $5 \mathrm{mC} / \mathrm{kg}$, decreasing spraying height regime to $34 \mathrm{~cm}, 23 \mathrm{~cm}$ and $12 \mathrm{~cm}$ continuously increased chargeability from $7.4 \mathrm{mC} / \mathrm{kg}, 7.6 \mathrm{mC} / \mathrm{kg}$ to $8.2 \mathrm{mC} / \mathrm{kg}$ respectively at $2.5 \mathrm{kV}$ applied voltage; indicating that the shorter the spraying height, the higher the charge-mass ratio and vice versa will be. Although, chargeability is the governing principle in electrostatic spraying of pesticides, the concept of spray coverage must be taken into consideration. Due to the force of attraction by the substrate architecture, a compensation of chargeability for ground coverage is desirable for spraying efficiency. It presupposes that, while aiming at higher applied droplet charge for efficient deposition, surface coverage should be taken into consideration as well for pesticide application. Therefore, charging droplets at $50 \mathrm{~cm}$ height as in conventional system should be factored during electrostatic system parameters settings. This is because, at spraying height of $0.35 \mathrm{~m} 0.65 \mathrm{~m}$ and $0.95 \mathrm{~m}$ from the target surface, the measured spray swath was $0.31 \mathrm{~m}, 0.42 \mathrm{~m}$ and $0.53 \mathrm{~m}$ respectively ${ }^{[19]}$. Also, chargeability decreased upon increasing spraying distance between the nozzle tip and the substrate from 0 to $5 \mathrm{~m}^{[45]}$. The closest distance produced $4.11 \mathrm{mC} / \mathrm{kg}$, while the farthest distance gave $0.052 \mathrm{mC} / \mathrm{kg}$. From the study, $1 \mathrm{~m}, 2 \mathrm{~m}$, $3 \mathrm{~m}$ and $4 \mathrm{~m}$ spraying distances produced respectively $1.38 \mathrm{mC} / \mathrm{kg}$, $0.64 \mathrm{mC} / \mathrm{kg}, 0.31 \mathrm{mC} / \mathrm{kg}$ and $0.17 \mathrm{mC} / \mathrm{kg}$ charge-mass ratio. This meant that increasing spraying distance beyond $1 \mathrm{~m}$ significantly decreased droplets charge. However, the study failed to consider how the vertical position of the nozzle influenced spray droplets characteristics.

\section{Electrostatic droplets characteristics from pesticides spray}

Charged droplets characteristics are the behavior and trajectory of finely divided particulate spray droplets from the electrostatic application. Those include the droplet sizes, the volume median diameter (VMD), the spray swath, the uniformity coefficient, the deposition density, the relative span factor, the spray volume deposition, the droplet velocity and the charge-mass ratio (CMR). Properties of these charged droplets characteristics vary on different surfaces of either abaxial or adaxial orientation ${ }^{[24]}$. Among all the droplet characteristics from electrostatic spraying of pesticides, the charge-mass ratio is considered as one of the most significant droplets characteristics to evaluate the functionality of spray. The CMR that determines the effectiveness of electrostatic spray system is the relative effort of electrical forces to overcome both gravitational force and kinetic energy entrained in spray droplets $^{[25]}$. CMR is the most critical parameter needed to effectively forecast charged droplets exposed to electrical, inertial and gravitational forces behavior ${ }^{[30]}$. It measures droplets chargeability from voltage application of an embedded electrode in the nozzle aperture at time of rupture with respect to liquid flow rate. The charge-mass ratio is influenced by the applied electrode voltage, the target to nozzle distance and the prevailing wind current ${ }^{[41]}$. The CMR increases with an applied electrical voltage to a critical point, remains constant and begins to decrease upon increasing the applied voltage to spray droplets electrostatically. Generally, suitable charge-mass ratio for pesticide spraying varies in the range from $0.001 \mathrm{C} / \mathrm{kg}$ to $0.002 \mathrm{C} / \mathrm{kg}^{[63]}$, but the lower charge-mass ratio of $0.0005 \mathrm{C} / \mathrm{kg}$ are also utilized for effective pesticide application electrostatically ${ }^{[44]}$. In recent studies, higher CMR has been deduced for pesticide spraying. At an entrained droplets charge $\left(i_{s}\right)$ measured in Coulomb $(\mathrm{C})$ and liquid flow rate $\left(Q_{m}\right)$ in kilogram per second $(\mathrm{kg} / \mathrm{s})$, the ratio of charge to mass $(\mathrm{CMR})$ is calculated ${ }^{[18,24,25]}$.

$$
C M R=i_{s} / Q_{m}
$$

In electrostatic spraying, an entrained charge of micro droplet sizes is higher than macro droplet sizes from equal liquid formulation whereas variations in applied spray pressure also influence droplet sizes ${ }^{[24]}$. Droplet sizes, spectrum, and evenness produced by electrostatic knapsack sprayers differed from that of conventional sprayers. The electrostatic sprayer produced smaller droplet sizes $(85.6 \mu \mathrm{m})$ and spectrum $(104 \mu \mathrm{m})$ but greater evenness (0.72) as compared to conventional sprayer of larger droplet sizes $(121 \mu \mathrm{m})$ and spectrum $(165 \mu \mathrm{m})$ but lower evenness $(0.68)^{[64]}$. These droplet characteristics were within the ideal range for effective pesticide deposition on substrates in the electrostatic application of pesticides. Enhancing spray deposition, retention and coverage on substrates need more droplets from a formulation at relatively smaller sizes to overcome spray drift ${ }^{[65]}$. The smaller the droplet sizes, the greater the numbers for the same formulation. The optimum droplet sizes for effective spraying should be at about VDM of $81.8 \mu \mathrm{m}^{[39]}$. The charge-mass ratio from larger droplets is also lower than smaller droplet sizes in electrostatic spraying system ${ }^{[66]}$. Smaller droplets size less than $150 \mu \mathrm{m}$ for $\operatorname{grasses}^{[67]}$, and $150-450 \mu \mathrm{m}$ for trees ${ }^{[68]}$, had been reported to be effective for deposition and phytotoxicity. However, the study failed to indicate the droplet sizes suitable to cause an effect on other plant classifications such as shrubs and dicot weeds. Less than $500 \mu \mathrm{m}$ average droplet diameter and $5.0 \mathrm{mC} / \mathrm{kg}$ charge-mass ratio at $140 \mathrm{kPa}$ application pressure have been deduced from a hydraulic nozzle in electrostatic application system $^{[28]}$.

A developed electrostatic nozzle has been used to produce $116 \mu \mathrm{m}$ volume median diameter from pesticide spray droplets where increased in applied voltages resulted in a decrease in volume median diameter ${ }^{[29]}$. Again, in Western et al. ${ }^{[69]}$, 
increasing application speed invariably increased the charge-mass ratio and volume median diameter (VDM). A lower application speed of $0.5 \mathrm{~m} / \mathrm{s}$ produced a lower charge-mass ratio of $2.0 \mathrm{mC} / \mathrm{kg}$ and higher VDM of $124 \mu \mathrm{m}$, whereas higher speed at $2 \mathrm{~m} / \mathrm{s}$ yielded charge-mass ratio of $9.5 \mathrm{mC} / \mathrm{kg}$ with lower VDM of $48 \mu \mathrm{m}$. An entrained smaller charge in larger spray droplets enhances canopy penetration with poor deposition than smaller spray droplets in air-assisted electrostatic spraying. For an electrostatic application of glyphosate, higher VDM of $112.8 \mu \mathrm{m}$ was measured at $10.0 \mathrm{kV}$ applied voltage ${ }^{[50]}$. Also, volume median diameter of $115 \mu \mathrm{m}$ and $1.85 \mathrm{mC} / \mathrm{kg}$ charge-mass ratio were obtained in an experiment to inject charges to spray droplets from hydraulic nozzles at $400 \mathrm{kPa}$ spray pressure and $0.45 \mathrm{~L} / \mathrm{min}$ liquid flow rate ${ }^{[70]}$. The above droplet sizes are suitable for effective deposition and interactive effect in electrostatic spraying system. Though smaller droplet sizes, the entrained charge enables them to overcome drift to non-target sites and to reduce environmental pollution.

\section{Electrostatic droplet impact behavior on the substrates}

Deposition of pesticides to target substrates is bedeviled with inefficiencies where $60 \%-70 \%$ of spray droplets find their way onto non-target sites as drift, while about $20 \%$ result in effective deposition on targeted substrates. Accordingly, the efficiency of spray deposition is expected to reach $80 \%$ under electrostatic application system while chemical usage is to cut-off by $50 \%$ during spraying ${ }^{[71-73]}$. This could be achieved only if optimum parameters combination that ensures maximum spray chargeability and ground coverage are adhered to during spraying. Though space charge decreases with an increasing spraying distance, achieving less than $1.5 \mathrm{mC}$ is suitable for droplets deposition ${ }^{[32]}$. The deposition efficiency is computed from spray relative deposition (RD) as a ratio of the quantity of intercepted spray droplets on the target surface to the total volume of spray applied $^{[19,74]}$.

$$
\begin{gathered}
R D=100[(M S /(A S / L A I))] \\
R D=100\left[\left(D /\left(Q_{a} / c\right)\right)\right]
\end{gathered}
$$

A maximum of $64 \%-76 \%$ relative deposition has been observed at application speed from $0.222 \mathrm{~m} / \mathrm{s}$ to $0.555 \mathrm{~m} / \mathrm{s}$ in electrostatic spraying system ${ }^{[75]}$. Although smaller droplet sizes (70-90 $\mu \mathrm{m})$ were produced by the electrostatic sprayer, the deposition loss could emanate from spraying height regimes of $20-60 \mathrm{~cm}$ orientation. Charging voltage, droplet velocity, substrate orientation, spraying height, and application speed are fundamental determinants of spray droplets deposition on target substrates $^{[19]}$. The attraction of charged droplets on substrates is dependent on electrode chargeability and liquid charge. However, for effective adsorption and deposition, substrate charge should be investigated to determine the ideal charge to inject onto the droplets.

From Law ${ }^{[32]}$, application of electrostatic principles in pesticide spraying is considered one of the options to ensure maximum underside droplets deposition where pests often hide to attack crops. In view of that, enhancing spray droplets deposition on abaxial leaf surfaces in electrostatic spraying system is paramount ${ }^{[64]}$. The electrostatic pesticide application is responsible for reducing off-target and maximizing on-target droplets deposition on substrates ${ }^{[35]}$. The requirement for on-target spray deposition and retention by electrostatic spraying system was necessitated to overcome the shortfalls in conventional pesticide spraying system where droplets drift enhanced edaphic imbalance, environmental pollution and human health risks factors $^{[4,76,77]}$. It is indicated that, upon charging droplets from $0 \mathrm{mC} / \mathrm{kg}$ to $5.5 \mathrm{mC} / \mathrm{kg}$ charge-mass ratio, spray deposition on abaxial leaf surfaces increased ${ }^{[19]}$. On abaxial surfaces, 0.66$1.33 \mu \mathrm{g} / \mathrm{cm}^{2}$ spray deposition was determined while adaxial surfaces recorded $0.78-1.79 \mu \mathrm{g} / \mathrm{cm}^{2}$ spray deposition at $30^{\circ}$ and $0^{\circ}$ orientations respectively. Also, at an applied voltage between 0-4.0 kV, spray deposition maximized on abaxial surfaces and minimized on adaxial surfaces at $0.417 \mathrm{~m} / \mathrm{s}$ and $0.278 \mathrm{~m} / \mathrm{s}$ ground speed rates respectively. However, Pascuzzi and Cerruto ${ }^{[36]}$ reported that forward speed has no significant effect on foliar deposition upon working with a pneumatic electrostatic sprayer at 4-6 $\mathrm{km} / \mathrm{h}$ rate. The differences in speed and equipment could account for the different results, hence the need for further research to select ideal speed for electrostatic pesticide spraying. Again, lowering spraying height accounts for higher deposition than higher height regimes because the ground base of the substrate attracts charged droplets to increase deposition as target height reduces. The phenomenon could be attributed to higher volumetric proportions of spray concentration on the substrate resulting in chemical overdose and higher application rate. In fact, plant species and pesticide formulation could have been used instead of the artificial plant and aqueous solution in that experiment for generalization in plant protection.

Electrostatic application of insecticide increased droplets deposition on electrically charged insects to annihilate domestic housefly by decreasing knockdown time at a high charge-mass ratio of $0.216 \mathrm{mC} / \mathrm{kg}^{[78]}$. The knockdown was subject to entrained charge possessed by the spray droplets plus the chemical active ingredient. Though an impressive result was achieved, the charge property of the insect was not ascertained. Additionally, control of whitefly and boll weevil in cotton fields were effective for electrostatic spraying where droplets were on pest specific. The pest seemed to possess opposite polarity of the charged droplets to cause attraction but data on it was not obtained. In cotton production, charging spray droplets improved on abaxial spray deposition, uniform surface coverage, and bio-efficacy. The charged spray droplets created wraparound effect ${ }^{[69,79]}$ to exterminate hidden insect pests ${ }^{[80]}$. Spray deposition at the underside of citrus leaves to control whitefly also improved bio-efficacy from airblast electrostatic sprayers ${ }^{[73]}$, while that of grape leaves was $200 \%$ effective ${ }^{[70]}$. The positive results were achieved due to oppositely charged polarity between the charged droplets and the substrates ions.

In orchard spraying, Laryea and $\mathrm{No}^{[29]}$ applied $4.0 \mathrm{kV}$ voltage at $2400 \mathrm{kPa}$ pressure to produce $0.27 \mathrm{mC} / \mathrm{kg}$ which enhanced droplets deposition by $130 \%$. The technology aimed at improving spatial distribution of droplets on the canopy and awkward surfaces unable to be covered under conventional spraying system. Electrostatic application of pesticide on cauliflower leaves yielded droplets deposition higher on the adaxial than abaxial surfaces as compared to conventional spraying system ${ }^{[72]}$. On smooth pigweed, 96\% droplets deposition was achieved while that on giant foxtail leaves rose to $345 \%$ when sprayed electrostatically from $50 \mathrm{~cm}$ height regime at $45 \mathrm{kV}$ applied electrode voltage ${ }^{[73]}$. The conditions that led to the disparities in deposition efficiencies as either atmospheric charge, wind interference, leaf surface texture or substrate charge segregations were not ascertained. Addressing these fundamental issues during pesticide spraying stand the chance of improving spraying efficiency. These results suggest that the electrostatic principle has been extensively applied in agriculture to 
enhance deposition and to control the pest. Due to some inefficiencies in the deposition of charged droplets, there is the need to test the charge capacity of the substrate prior to spraying to overcome repulsive charged droplets of some plants with the same charge. Plants and insect pests differ in architecture, so without knowing their charged properties, achieving complete deposition would be difficult, no matter the voltage superposition.

\section{Summary and conclusions}

1) Electrostatics principle is applied in agriculture to superpose charges to pesticide spray droplets to improve on both abaxial and adaxial surfaces deposition, retention, and coverage. In operation, the electrode material is embedded in a nozzle aperture to charge droplets before rupture onto substrates at applied voltages, applied pressures, spraying height regimes, flow rates, and travel speed. So far, induction charging has been considered the most suitable method, as compared to charging by conduction, corona and triboelectrification principles, to enhance pesticide spray deposition and coverage. The mechanism for electrostatic pesticides spraying initiates as electrodynamics, through hydrodynamics to the final phase of aerodynamics. Since the inception of electrostatic crop spraying, efforts have been made to optimize the process by varying the system parameters. However, there is unknown specific optimum parameters combination for effective spraying at all levels. Therefore, parameters that produce suitable charge-mass ratio contribute to the functionality of spray deposition, retention and surface coverage, since droplets chargeability determines the effectiveness of the electrostatic spray system.

2) In electrostatic spraying of pesticides, extensive researches have been conducted on different system parameters to achieve different droplet characteristics and impact behaviors on substrates. Both cone and flat fan nozzle types have been mounted on manual, tractor, man-aerial and unmanned-aerial sprayers for electrostatic spraying. In the nozzle cap, stainless steel, brass, and copper at variable voltage capacities are commonly used as electrode materials. There is, therefore, the need to choose suitable electrode properties that can maximize chargeability at minimum power supply, such that many nozzles can be mounted on the boom at minimum apply voltage. Often, air-assisted induction nozzle types, electrode distances, spraying heights and system parameters combinations are adopted to produce suitable charge to mass ratio for pesticide spraying. Though the nozzles worked to the required demand, increasing the tip angle and spraying height to maximize surface coverage could reduce operation time and chemical dosage. This is because the charged droplets have the capability to be attracted to the substrate ions irrespective of the droplet direction. At lower spraying heights, over concentration of charged droplets to cause pesticide overdose ensues during spraying.

3) From the review, among all the droplet characteristics from electrostatic spraying of pesticides, the charge-mass ratio was considered as one of the most significant droplets characteristics to evaluate the functionality of spray. Besides, droplets sizes, relative span, velocity, and spray swath determines the extent of pesticide spraying efficiency. Increasing applied voltage and pressure to spray droplets at lower spraying height regimes were observed to maximize charge to mass ratio. But the lower the height, the smaller the ground coverage, a phenomenon prone to reduce spraying efficiency. Hence increasing both applied voltage, pressure and height to the optimum is postulated in this article. The CMR is the relative effort of electrical forces to overcome both gravitational force and kinetic energy entrained in spray droplets. Adsorption of charged droplets by substrates is maximized at higher entrained droplets charge and smaller droplet sizes.

4) Thanks to the electrostatic application in pesticide spraying, droplets deposition, impinging, rebound and drift inefficiencies have been reduced due to substrate attraction. There has been the wraparound effect of droplets pinning on substrates to reduce off-target deposition, enhances on-target spray and invariably improves spray efficiency. The problem of abaxial deposition in the conventional spraying system has been appropriated, hence topside and underside spray droplets deposition are achieved in electrostatic spraying of pesticides. However, the combined effect of electrostatic charges on substrates charge to aid efficient deposition is unknown. The substrate charge may aid attraction or cause repulsion to droplets electric charge. To overcome this phenomenon, determination of substrate charge prior to electrostatic spraying of pesticides would invariably ensure effective deposition, impinging and retention on the substrate for interactive effect.

5) In line with this literature review on system parameters, droplet characteristics and impact behavior in electrostatic pesticide spraying, the paper puts forward the future trends to improve on pesticide application in plant protection:

a) Investigation of an optimum parameters combination to streamline the variations of parameters combination for pesticide spraying in an electrostatic spraying system.

b) Enhancement of electrode properties to minimize applied voltage supply in order to maximize nozzle numbers on the boom for electrostatic spraying of pesticides.

c) Determination of substrates charges or ions prior to pesticide application to superpose the right opposite charge polarity on spray droplets at rupture time during electrostatic spraying system.

d) Improving pesticides spray droplets deposition and interactive effect on substrates through surfactant inclusion in pesticide formulation during electrostatic spraying system.

e) The application of the electrostatic principle in the robotic spraying of pesticides to avert human hazards associated with pesticide spraying.

The electrostatic spraying system would work effectively at an optimum parameters combination because various parameters settings have been systematically adopted by researchers for the electrostatic application. The system parameters influence spray droplet characteristics and impact behavior, and the adoption of optimum parameters combination salvages pesticide spraying inefficiencies from chemical wastage and environmental pollution. Subject to pesticide-human toxicity ${ }^{[81,82]}$, recently, there is a paradigm shift from manual spraying (knapsacks) to man-vehicles (tractors and airplanes) and unmanned aerial vehicles such as drones. However, to completely cut-off human hazards associated with pesticides, there is the need to apply the electrostatic principle in robotic spraying of pesticides.

\section{Acknowledgements}

The authors would like to appreciate the financial support from the funds of the National Key Research and Development Plan of China (grant number 2016YFD0200700), the National Natural Science Foundation of China (grant number 51475215, 31601676), and the Advanced Talent Research Funding of Jiangsu University (grant number 5501200004). 


\section{Appendix}

\begin{tabular}{cl}
\hline Nomenclature & \\
\hline$F_{1}$ & Coulombic Force $(\mathrm{N})$ \\
$F_{2}$ & Gravitational force $(\mathrm{N})$ \\
$q$ & Electric charge $(\mathrm{C})$ \\
$E$ & Electric field $(\mathrm{N} / \mathrm{C})$ \\
$m$ & Mass of particle $(\mathrm{g})$ \\
$g$ & Gravitational constant $\left(\mathrm{m}^{2} / \mathrm{s}\right)$ \\
$D$ & Tracer deposition per unit target area $\left(\mu \mathrm{g} / \mathrm{cm}^{2}\right)$ \\
$Q_{a}$ & Theoretical volume of spray liquid applied per unit area $\left(\mathrm{mL} / \mathrm{cm}^{2}\right)$ \\
$c$ & Concentration of tracer in the spray liquid $(\mu \mathrm{g} / \mathrm{mL})$ \\
$R D$ & Relative deposition $(\%)$ \\
$A S$ & Theoretical deposition on unit surface $\left(\mu \mathrm{g} / \mathrm{cm}^{2}\right)$ \\
$M S$ & Mean stardust deposition determined on filter papers per zone of \\
$L A I$ & a sprayer $\left(\mu \mathrm{g} / \mathrm{cm}^{2}\right)$ \\
\hline
\end{tabular}

\section{[References]}

[1] Abhilash P, Singh N. Pesticide use and application: an Indian scenario. Journal of Hazardous Materials, 2009; 165(1-3): 1-12.

[2] Huang Y, Thomson S J, Hoffmann W C, Lan Y, Fritz B K. Development and prospect of unmanned aerial vehicle technologies for agricultural production management. Int J Agric \& Biol Eng, 2013; 6(3): 1-10.

[3] Chambers J E, Greim H, Kendall R J, Segner H, Sharpe R M, Van Der Kraak G. Human and ecological risk assessment of a crop protection chemical: a case study with the azole fungicide epoxiconazole. Critical Reviews in Toxicology, 2014; 44(2): 176-210.

[4] Guthman J, Brown S. I will never eat another strawberry again: the biopolitics of consumer-citizenship in the fight against methyl iodide in California. Agriculture and Human Values, 2016; 33(3): 575-585.

[5] Hegab M F A H, Ayoub F H, Badran B A, Mona I, Ammar M I. New approaches to control cucumber pest infestation with emphasis on productivity and crop characteristics under greenhouse conditions. Egypt. J. Agric. Res., 2016; 94(3): 673-688.

[6] Zhang W, Hou Y R, Liu X, Lian Q, Fu X M, Zhang B, et al. Wind tunnel experimental study on droplet drift reduction by a conical electrostatic nozzle for pesticide spraying. Int J Agric \& Biol Eng, 2017; 10(3): $87-94$.

[7] Wang J, Lan Y B, Zhang H H, Zhang Y L, Wen S, Yao W X, et al. Drift and deposition of pesticide applied by UAV on pineapple plants under different meteorological conditions. Int J Agric \& Biol Eng, 2018; 11(6): $5-12$.

[8] Gil E, Gallart M, Balsari P, Marucco P, Almajano M P, Llop J. Influence of wind velocity and wind direction on measurements of spray drift potential of boom sprayers using drift test bench. Agricultural and Forest Meteorology, 2015; 202: 94-101.

[9] Damak M, Mahmoudi S R, Hyder M N, Varanasi K K. Enhancing droplet deposition through in-situ precipitation. Nature Communications, 2016; 7: 12560. https://doi:10.1038/ncomms 12560

[10] Lin H, Zhou $\mathrm{H}$, Xu L, Zhu H, Huang $\mathrm{H}$. Effect of surfactant concentration on the spreading properties of pesticide droplets on Eucalyptus leaves. Biosystems Engineering, 2016; 143: 42-49.

[11] Nuyttens D, Baetens K, De Schampheleire M, Sonck B. Effect of nozzle type, size and pressure on spray droplet characteristics. Biosystems Engineering, 2007; 97(3): 333-345.

[12] Taylor W, Womac A, Miller P, Taylor B. An attempt to relate drop size to drift risk. Paper presented at the Proceedings of the International Conference on Pesticide Application for Drift Management, 2004.

[13] Klein R N, Golus J A, Nelms K L. The Effect of Adjuvants, Pesticide Formulation, and Spray Nozzle Tips on Spray Droplet Size. Journal of ASTM International, 2009; 6(6): 1-7.

[14] Doruchowski G, Hołownicki R, Godyń A, Świechowski W. Sprayer calibration training-concept and performance. Paper presented at the Fourth European Workshop on Standardised Procedure for the Inspection of sprayers, SPISE, 2012.

[15] Laryea G, No S. Spray angle and breakup length of charge-injected electrostatic pressure-swirl nozzle. Journal of Electrostatics, 2004; 60(1):
37-47.

[16] Martini A T, Avila L A, Camargo E R, Helgueira D B, Bastiani M O, Loeck A E. Pesticide drift from aircraft applications with conical nozzles and electrostatic system. Ciência Rural, 2016; 46(9): 1678-82.

[17] Esehaghbeygi A, Tadayyon A, Besharati S. Comparison of electrostatic and spinning-discs spray nozzles on wheat weeds control. Journal of American Science, 2010; 6(10): 529-533.

[18] Mamidi V R, Ghanshyam C, Kumar P M, Kapur P. Electrostatic hand pressure knapsack spray system with enhanced performance for small scale farms. Journal of Electrostatics, 2013; 71(4): 785-790.

[19] Maski D, Durairaj D. Effects of charging voltage, application speed, target height, and orientation upon charged spray deposition on leaf abaxial and adaxial surfaces. Crop Protection, 2010; 29(2): 134-141.

[20] Miller P C E, Butler-Ellis M C. Effects of formulation on spray nozzle performance for applications from ground-based boom sprayers. Crop Protection, 2000; 19: 609-615.

[21] Vallet A, Tinet C. Characteristics of droplets from single and twin jet air induction nozzles: A preliminary investigation. Crop Protection, 2013; 48 63-68.

[22] Ferguson J C, O'Donnell C C, Chauhan B S, Adkins S W, Kruger G R, Wang R, et al. Determining the uniformity and consistency of droplet size across spray drift reducing nozzles in a wind tunnel. Crop Protection, 2015; 76: 1-6.

[23] Mostafaie Maynagh B, Ghobadian B, Tavakkoli Hashjin T, Jahannama M. Effect of electrostatic induction parameters on droplets charging for agricultural application. Journal of Agricultural Science and Technology, 2009; 11: 249-257.

[24] Patel M K, Praveen B, Sahoo H K, Patel B, Kumar A, Singh M, et al. An advance air-induced air-assisted electrostatic nozzle with enhanced performance. Computers and Electronics in Agriculture, 2017; 135: 280-288.

[25] Maski D, Durairaj D. Effects of electrode voltage, liquid flow rate, and liquid properties on spray chargeability of an air-assisted electrostatic-induction spray-charging system. Journal of Electrostatics, 2010; 68(2): 152-158.

[26] Osman H. "Charging level and deposition of droplets in electrostatic painting" Electronic Thesis and Dissertation Repository, 2015; 3235. https://ir.lib.uwo.ca/etd/3235

[27] Zhao S, Castle G P, Adamiak K. Comparison of conduction and induction charging in liquid spraying. Journal of Electrostatics 2005; 63: 871-876.

[28] Hensley J L, Feng X, Bryan J E. Induction charging nozzle for flat fan sprays. Journal of Electrostatics, 2008; 66(5-6): 300-311.

[29] Laryea G N, No S-Y. Development of electrostatic pressure-swirl nozzle for agricultural applications. Journal of Electrostatics, 2003; 57(2): 129-142.

[30] Toljic N, Adamiak K, Castle G. Determination of particle charge to mass ratio distribution in electrostatic applications: a brief review. Paper presented at the Proc. ESA Annual Meeting on Electrostatics, 2008.

[31] Law S E. Electrostatic pesticide spraying: concepts and practice. IEEE transactions on Industry Applications, 1983; 2: 160-168.

[32] Law S E. Agricultural electrostatic spray application: a review of significant research and development during the 20th century. Journal of Electrostatics, 2001; 51: 25-42.

[33] Mamidi V R, Ghanshyam C, Patel M K, Kapur P. Electrostatic hand pressure swirl nozzle for small crop growers. Int. J. Appl. Sci. Technol. Res. Excell, 2012; 2(2): 164-168.

[34] Chigier N. Challenges for future research in atomization and spray technology: Arthur lefebvre memorial lecture. Atomization and Sprays, 2006; 16(7): 727-736.

[35] Toljic N, Adamiak K, Castle G, Kuo H-H H, Fan H-T C. Three-dimensional numerical studies on the effect of the particle charge to mass ratio distribution in the electrostatic coating process. Journal of Electrostatics, 2011; 69(3): 189-194

[36] Kirk I, Hoffmann W, Carlton J. Aerial electrostatic spray system performance. Transactions of the ASAE, 2001; 44(5): 1089.

[37] Pascuzzi S, Cerruto E. Spray deposition in "tendone" vineyards when using a pneumatic electrostatic sprayer. Crop Prot., 2015; 68: 1-11.

[38] Yamane S, Miyazaki M. Charging performance of an electrostatic pesticide spraying system for low-concentration and high-volume applications. Journal of the Japanese Society of Agricultural Machinery, 2008; 70(4): 115-122.

[39] Yamane S, Miyazaki M. Study on electrostatic pesticide spraying system 
for low-concentration, high-volume applications. Japan Agricultural Research Quarterly: JARQ, 2017; 51(1): 11-16.

[40] Ru Y, Zheng J Q, Zhou H P, Shu C R. Design and experiment of double-nozzle of aerial electrostatic sprayer. Transactions of the CSAM, 2007; 38(5): 58-61. (in Chinese)

[41] Zhang Y L, Lian Q, Zhang W. Design and test of a six-rotor unmanned aerial vehicle (UAV) electrostatic spraying system for crop protection. Int J Agric \& Biol Eng, 2017; 10(6): 68-76.

[42] Patel M K, Kundu M, Sahoo H K, Nayak M K. Enhanced performance of an air-assisted electrostatic nozzle: Role of electrode material and its dimensional considerations in spray charging. Engineering in Agriculture, Environment and Food, 2016; 9(4): 332-338.

[43] Ru Y, Zhou H, Jia Z, Wu X, Fan Q. Design and application of electrostatic spraying system. Journal of Nanjing Forestry University: Natural Science Edition, 2011; 35(1): 91-94.

[44] Patel M K, Sahoo H K, Nayak M K, Kumar A, Ghanshyam C, Kumar A. Electrostatic nozzle: new trends in agricultural pesticides spraying. SSRG International Journal of Electrical and Electronics Engineering, 2015; 6-11.

[45] Law S. Electrostatics technology for agricultural and biological applications: status and trends. Electrostatics, 1995; 143: 1-12.

[46] Sasaki R. S, Teixeira M. M, Fernandes H C, Monteiro P M d. B, Rodrigues D E, Alvarenga C B d. Parameters of electrostatic spraying and its influence on the application efficiency. Revista Ceres, 2013; 60: 474-479.

[47] Patel M K, Sahoo H K, Nayak M K, Ghanshyam C. Plausibility of variable coverage high range spraying: Experimental studies of an externally air-assisted electrostatic nozzle. Computers and Electronics in Agriculture, 2016; 127: 641-651.

[48] Moon J-D, Lee D-H, Kang T-G, Yon K-S. A capacitive type of electrostatic spraying nozzle. Journal of Electrostatics, 2003; 57(3-4): 363-379.

[49] Gupta C, Duc T. Deposition studies of a hand-held air-assisted electrostatic sprayer. Transactions of the ASAE, 1996; 39(5): 1633-1639.

[50] Martin D E, Latheef M A. Aerial electrostatic spray deposition and canopy penetration in cotton. Journal of Electrostatics, 2017; 90: 38-44.

[51] Matthews G. Pesticide application: Current status and further developments: Springer, 1997.

[52] Patel M K, Ghanshyam C, Mamidi V R, Kapur P. Performance and characterization of different material electrodes in electrostatic pesticide spraying nozzle system, Int. J. Appl. Sci. Technol. Res. Excell, 2012; 2(2): $158-163$

[53] Wang D-W, Li F, Cheng H-M. Hierarchical porous nickel oxide and carbon as electrode materials for asymmetric supercapacitor. Journal of Power Sources, 2008; 185(2): 1563-1568.

[54] Janmanee P, Muttamara A. Performance of difference electrode materials in electrical discharge machining of tungsten carbide. Energy Research Journal, 2010; 1(2): 87-90.

[55] Xu B, Fell C R, Chi M, Meng Y S. Identifying surface structural changes in layered Li-excess nickel manganese oxides in high voltage lithium ion batteries: A joint experimental and theoretical study. Energy \& Environmental Science, 2011; 4(6): 2223-2233.

[56] Patel M K, Ghanshyam C, Kapur P. Characterization of electrode material for electrostatic spray charging: Theoretical and engineering practices. Journal of Electrostatics, 2013; 71(1): 55-60.

[57] Law S, Thompson S, Balachandran W. Electroclamping forces for controlling bulk particulate flow: Charge relaxation effects. Journal of Electrostatics, 1996; 37(1-2): 79-93.

[58] Maski D. Spray chargeability studies and data modeling using electrostatic spraying system for drift mitigation. Paper presented at the 2005 ASAE Annual Meeting, 2005.

[59] Jahannama M R, Watkins A P, Yule A J. Electrostatic effects on agricultural air-atomized sprays and deposition. Part I: An experimental study. Atomization and Sprays, 2005; 15(6): 629-660.

[60] Huang Y B, Ouellet-Plamondon C M, Thomson S J, Reddy K N. Characterizing downwind drift deposition of aerially applied glyphosate using $\mathrm{RbCl}$ as tracer. Int J Agric \& Biol Eng, 2017; 10(3): 31-36.
[61] Nuyttens D, De Schampheleire M, Baetens K, Sonck B. The influence of operator-controlled variables on spray drift from field crop sprayers. Transactions of the ASABE, 2007; 50(4): 1129-1140.

[62] Zhao S, Castle G S P, Adamiak K. The effect of space charge on the performance of an electrostatic induction charging spray nozzle. Journal of Electrostatics, 2005; 63(3): 261-272.

[63] Hislop E C. Electrostatic ground-rig spraying: an overview. Weed Technology, 1988; 2(1): 94-105.

[64] He Y, Zhao B, Yu Y. Effect, comparison and analysis of pesticide electrostatic spraying and traditional spraying. Bulgarian Chemical Communications, 2016; 48: 340-344.

[65] Felsot A S, Unsworth J B, Linders J B, Roberts G, Rautman D, Harris C, et al. Agrochemical spray drift; assessment and mitigation-A review. Journal of Environmental Science and Health Part B, 2010; 46(1): 1-23.

[66] Zhao S, Castle G, Adamiak K. Factors affecting deposition in electrostatic pesticide spraying. Journal of Electrostatics, 2008; 66(11-12) 594-601.

[67] Knoche M. Effect of droplet size and carrier volume on performance of foliage-applied herbicides. Crop Protection, 1994; 13(3): 163-178.

[68] Prasad R, Cadogan B L. Influence of droplet size and density on phytotoxicity of three herbicides. Weed Technology, 1992; 6(2): 415-423.

[69] Western N, Hislop E, Dalton W. Experimental air-assisted electrohydrodynamic spraying. Crop Protection, 1994; 13(3): 179-188.

[70] Gan-Mor S, Ronen B, Ohaliav K. The effect of air velocity and proximity on the charging of sprays from conventional hydraulic nozzles. Biosystems Engineering, 2014; 121: 200-208.

[71] Giles D, Blewett T. Effects of Conventional and Reduced-Volume, Charged-Spray Application Techniques on Dislodgeable Foliar Residue of Captan on Strawberries. Journal of Agricultural and Food Chemistry, 1991; 39(9): 1646-1651.

[72] Palumbo J C, Coates W E. Air-assisted electrostatic application of pyrethroid and endosulfan mixtures for sweet potato whitefly (Homoptera aleyrodidae) control and spray deposition in cauliflower. Journal of Economic Entomology, 1996; 89(4): 970-980.

[73] Wolf T M, Downer R A, Hall F R, Wagner O B, Kuhn P. Effect of electrostatic charging on the dose transfer of water-based pesticide mixtures, Pesticide Formulations and Application Systems: 15th Volume: ASTM International, 1996.

[74] Bayat A, Zeren Y, Ulusoy M. Spray deposition with conventional and electrostatically-charged spraying in citrus trees. Agricultural Mechanization in Asia Africa and Latin America, 1994; 25: 35-35.

[75] Babu M R, Singh G, Gupta C P. Comparative performance of hand sprayers using different application techniques. Agricultural Mechanization in Asia Africa and Latin America, 1990; 21(2): 27-32.

[76] He X K, Zeng A J, Liu Y J, Song J L. Precision orchard sprayer based on automatically infrared target detecting and electrostatic spraying techniques. Int J of Agric \& Biol Eng, 2011; 4(1): 35-40.

[77] Ezhilarasi P, Karthik P, Chhanwal N, Anandharamakrishnan C. Nanoencapsulation techniques for food bioactive components: A review. Food and Bioprocess Technology, 2013; 6(3): 628-647.

[78] Gaunt L F, Hughes J F, Harrison N M. Electrostatic deposition of charged insecticide sprays on electrically isolated insects. Journal of Electrostatics, 2003; 57(1): 35-47.

[79] Carlton J, Bouse L, Kirk I. Electrostatic charging of aerial spray over cotton. Transactions of the ASAE, 1995; 38(6): 1641-1645.

[80] Maski D, Durairaj C D. Abaxial Deposition and Biological Efficacy of Electrostatically Charged Spray. Paper presented at the ASABE Annual International Meeting, July 9-12, 2006, Portland, OR, USA.

[81] Hart E, Coscollà C, Pastor A, Yusà V. GC-MS characterization of contemporary pesticides in PM10 of Valencia Region, Spain. Atmos. Environ, 2012; 62: 118-129.

[82] Coscollà C, López A, Yahyaoui $\mathrm{A}$, Colin $\mathrm{P}$, Robin $\mathrm{C}$, Poinsignon $\mathrm{Q}$, Yusà V. Human exposure and risk assessment to airborne pesticides in a rural French community. Science of the Total Environment, 2017; 584-585: $856-868$. 